\title{
Osseous Sarcoidosis with a Solitary Lytic Skull Lesion: A Case Report
}

\author{
Vignaraja Thirunavukarasu, MBBS, BSc, MPhil (Med) ${ }^{1}$ Caitlin Thirunavukarasu, MBBS, BPharm² \\ Timothy Willis, MBBS $^{3}$ Antonio Tsahtsarlis, MBBS, FRACS ${ }^{1}$
}

\footnotetext{
${ }^{1}$ Department of Neurosurgery, Princess Alexandra Hospital, Brisbane, Queensland, Australia

2 Department of Internal Medicine, The Royal Brisbane and Women's Hospital, Brisbane, Queensland, Australia

3 Department of Anatomical Pathology, Princess Alexandra Hospital, Brisbane, Queensland, Australia
}

J Neurol Surg Rep 2019;80:e27-e29.

\author{
Address for correspondence Vignaraja Thirunavukarasu, MBBS, BSc, \\ MPhil (Med), Department of Neurosurgery, Princess Alexandra \\ Hospital, Woolloongabba, Brisbane 4102, QLD, Australia \\ (e-mail: victhiru@hotmail.com).
}

\author{
Abstract \\ Keywords \\ - osseous sarcoidosis \\ - neurosurgery \\ - histopathological \\ diagnosis \\ - skull sarcoid
}

\begin{abstract}
Bone sarcoidosis is an uncommon manifestation of the multisystemic disease with skull involvement being rare. We present the case of a 32-year-old female who was referred by her General Practitioner with a left calvarial lesion on a background of previous unilateral 7th nerve palsy and diabetes mellitus. Images demonstrated a left frontoparietal calvarial osteolytic lesion. She underwent resection by the neurosurgical team with histopathological study revealing noncaseating granulomas, consistent with sarcoidosis. Given absence of other systemic features of sarcoidosis, she did not undergo systemic treatment.
\end{abstract}

\section{Case Report}

A 32-year-old Caucasian female was referred to neurosurgical outpatients for evaluation of an asymptomatic left calvarial lesion. Past medical history was significant for type 2 diabetes mellitus and asthma, treated with metformin and inhaled fluticasone, respectively. On physical examination she was a morbidly obese lady (BMI $42.9 \mathrm{~kg} / \mathrm{m}^{2}$ ). She had no focal or abnormal neurological findings on examination.

The left frontoparietal calvarial osteolytic lesion, $1.3 \times 1.4 \mathrm{~cm}$, was incidentally detected on computerized tomography (CT) scan 2 years prior for evaluation of left sided 7th cranial nerve palsy which spontaneously resolved ( - Fig. 1). There was no associated focal enhancement and the leading differential at the time was of a simple benign hemangioma. Interval CT scan performed 18 months later reported an increase in size of the lesion to $1.6 \times 2.6 \mathrm{~cm}$ with new endosteal scalloping laterally and medially with the appearance of erosion through the parenchymal diploic cortex (-Fig. 2). Once again, there was no focal or meningeal enhancement.

Serial magnetic resonance imaging (MRI) of the brain demonstrated an enhancing, expansile lesion in the left frontal bone, increasing in size from $17 \times 7$ to $34 \times 13 \mathrm{~mm}$ over
2 years. There were no intracranial areas of abnormality or enhancement. Other investigations revealed an unremarkable full blood count and liver function tests. Corrected calcium was mildly low $2.24 \mathrm{mmol} / \mathrm{L}$ (range: $2.25-2.65 \mathrm{mmol} / \mathrm{L}$ ) with normal creatinine and phosphate. Serum angiotensin-converting enzyme (ACE) level was within normal limits. Chest X-ray was unremarkable. Bone scan was requested but the patient declined.

The lesion was resected with no postoperative neurological changes. Histopathological examination revealed large numbers of naked granulomas consistent with sarcoidosis (-Fig. 3). Rheumatological consult was sought with the diagnosis of localized sarcoidosis of the skull made. Given the absence of features of systemic sarcoidosis, the patient did not receive systemic therapy and is for surveillance follow-up in Rheumatology outpatients.

\section{Discussion}

Sarcoidosis is a systemic inflammatory disorder characterized by noncaseating granulomas. ${ }^{1}$ It can involve multiple organs including the lungs, lymph nodes, skin, and eyes with bone involvement being uncommon, affecting 3 to $13 \%$ of patients. ${ }^{2,3}$ received

March 22, 2018 accepted after revision January 18, 2019
DOI https://doi.org/

10.1055/s-0039-1687845. ISSN 2193-6358. (c) 2019 Georg Thieme Verlag KG
Stuttgart · New York

License terms

(1) $\Theta \circledast$ 


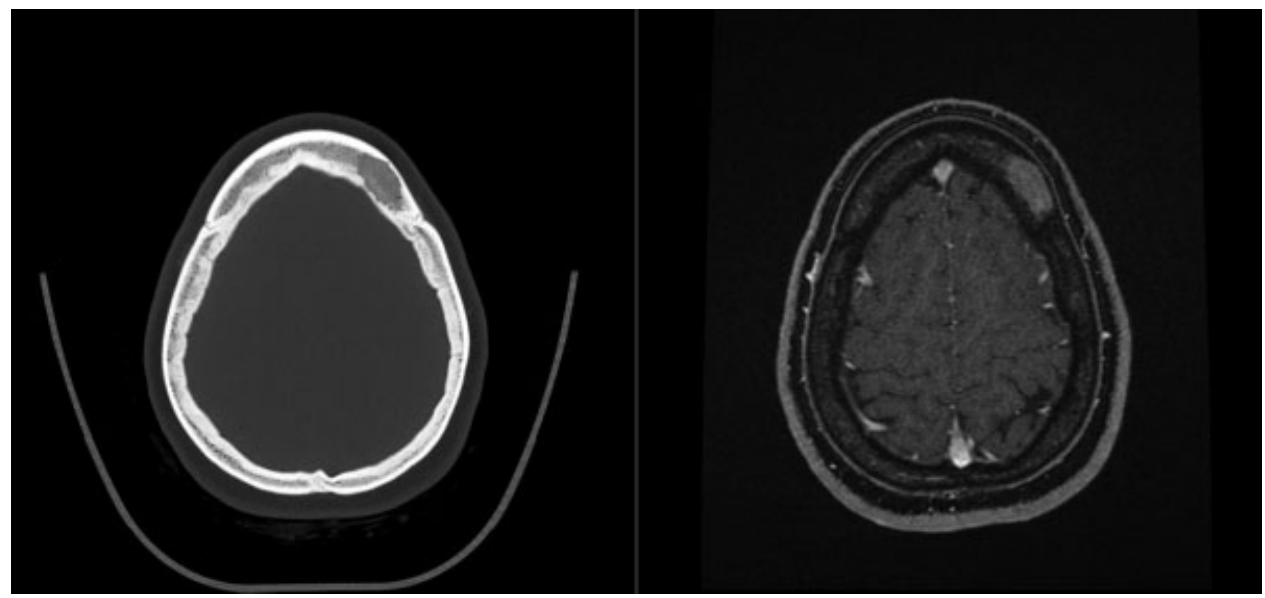

Fig. 1 Axial CT and contrast-enhanced MRI imaging of osseous lesion on diagnosis. CT, computerized tomography; MRI, magnetic resonance imaging.

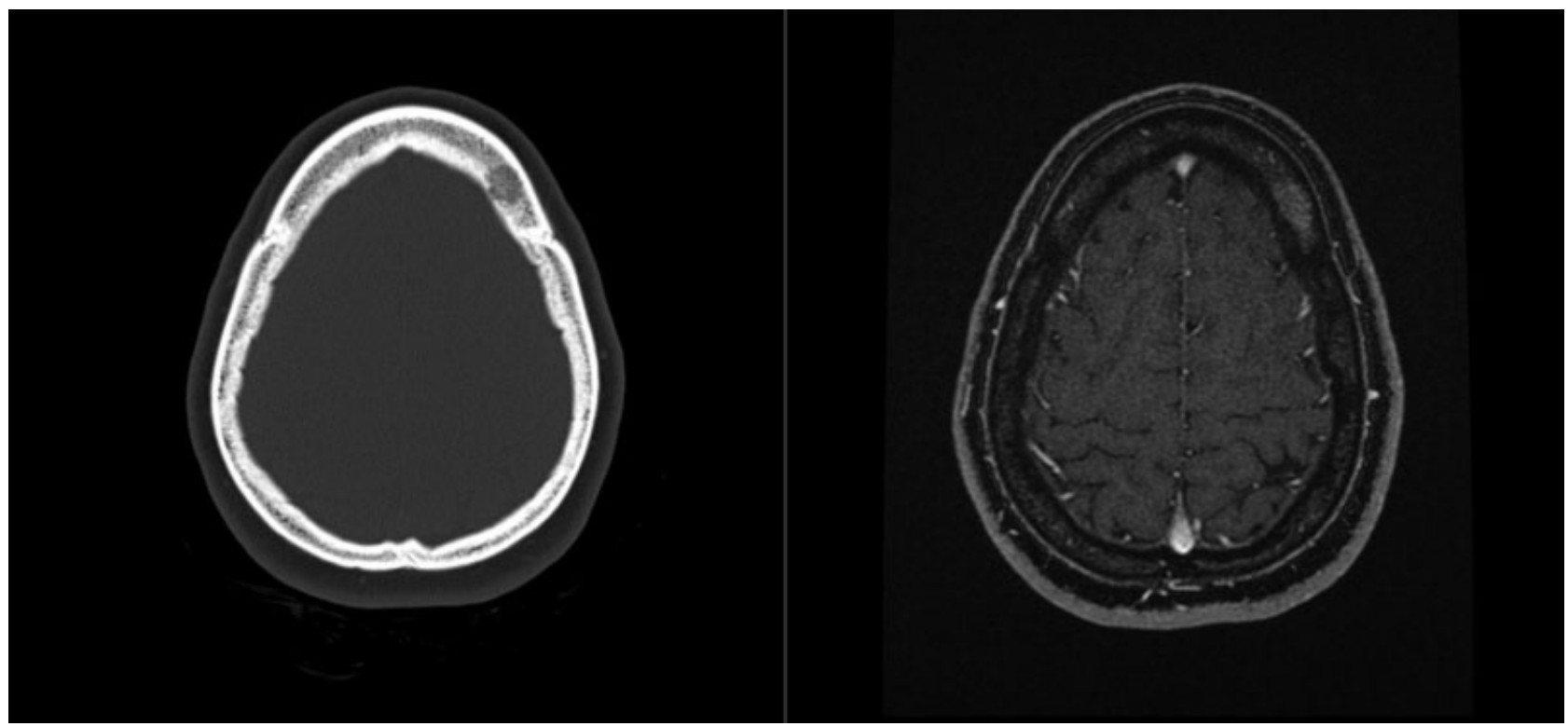

Fig. 2 Axial CT and contrast-enhanced MRI imaging of osseous lesion at 18-month follow-up. CT, computerized tomography; MRI, magnetic resonance imaging.



Fig. 3 Bone with fibrosis of marrow and "naked" nonnecrotising granulomas typical of sarcoidosis (Haematoxylin and Eosin).
Bone involvement generally occurs as part of chronic multisystem, extrathoracic disease, and has been associated with uveitis or lupus pernio. ${ }^{4,5}$ Osseous sarcoid as an initial presentation is extremely rare and multiple bones are usually involved. ${ }^{5}$

Further, osseous sarcoidosis affecting the skull is very rare, with the most frequent site of involvement being small tubular bones particularly of the hands and feet. ${ }^{4,6}$ The first case with sarcoidosis of the skull was described by Nielsen in 1934. A classic series of patients with osseous sarcoidosis by Neville in 1977 described only 1 patient out of 29 with skull involvement. ${ }^{4}$ A large series in Spain, conducted over 15 years with 425 patients, reported only one case with osteolytic skull lesions. ${ }^{7}$ The occurrence of solitary skull lesions is rare.

Radiographically, skull sarcoidosis most frequently appears as osteolytic lesions without reactive or sclerotic changes, although permeative and destructive patterns can occur. ${ }^{5,8}$ The lesions are asymptomatic in up to $50 \%$ of cases. ${ }^{9}$ The 
differential diagnosis for such lesions is broad and includes metastatic bone disease, multiple myeloma, lymphoma, infection, Paget's disease, and osseous hemangiomas. In the absence of prospective trials, optimal treatment of skull sarcoidosis is unknown with the role of systemic corticosteroids being uncertain $^{10}$ and the natural course unpredictable. ${ }^{11}$

An additional interesting point was the clinical history of unilateral 7th nerve palsy prior to the diagnosis of bony sarcoidosis. This raises the question of possible preceding neurosarcoidosis. This is an uncommon manifestation of sarcoidosis, occurring in 5\% of patients. ${ }^{12}$ Isolated neurosarcoidosis without other systemic signs is rare. ${ }^{13}$ MRI brain performed for our patient at the time of symptoms did not demonstrate any corresponding abnormality; however, it is reported that MRI abnormalities occur in only $70 \%$ of cases ${ }^{14}$; no further ancillary investigations, such as cerebrospinal fluid (CSF) examination, were performed. This reflects the literature as a definitive diagnosis is often not achieved; histopathological diagnosis is difficult and the clinical presentations are heterogeneous. A tentative diagnosis is often based on characteristic neurologic features in a patient with a systemic diagnosis of sarcoidosis. ${ }^{15}$

This case reiterates several important issues. It highlights that skull sarcoidosis, while exceptionally rare, should be considered in the differential diagnosis of osteolytic skull lesions, even in the absence of other chronic multisystem manifestations of sarcoidosis or multiple osseous lesions. It also reiterates the importance of biopsy, with the characteristic histopathological finding of noncaseating granulomas, to secure the diagnosis and direct management.

Conflict of Interest

None.

\section{References}

1 Mayock RL, Bertrand P, Morrison CE, Scott JH. Manifestations of sarcoidosis. Analysis of 145 patients, with a review of nine series selected from the literature. Am J Med 1963;35:67-89

2 Shorr AF, Murphy FT, Gilliland WR, Hnatiuk W. Osseous disease in patients with pulmonary sarcoidosis and musculoskeletal symptoms. Respir Med 2000;94(03):228-232

3 James DG, Neville E, Siltzbach LE. A worldwide review of sarcoidosis. Ann N Y Acad Sci 1976;278:321-334

4 Neville E, Carstairs LS, James DG. Sarcoidosis of bone. Q J Med 1977;46(182):215-227

5 Zisman DA, Shorr AF, Lynch JP III. Sarcoidosis involving the musculoskeletal system. Semin Respir Crit Care Med 2002;23 (06):555-570

6 Sparks JA, McSparron JI, Shah N, et al. Osseous sarcoidosis: clinical characteristics, treatment, and outcomes-experience from a large, academic hospital. Semin Arthritis Rheum 2014;44(03): 371-379

7 Badrinas F, Morera J, Fité E, et al. [Sarcoidosis in Catalonia: analysis of 425 cases]. Med Clin (Barc) 1989;93(03):81-87

8 Slart RM, de Jong JW, Haeck PW, Hoogenberg K. Lytic skull lesions and symptomatic hypercalcaemia in bone marrow sarcoidosis. J Intern Med 1999;246(01):117-120

9 Atanes A, Gómez N, de Toro FJ, et al. [The bone manifestations in 94 cases of sarcoidosis]. Med Interna 1991;8(10):481-486

10 Teirstein AS, Wolf BS, Siltzbach LE. Sarcoidosis of the skull. N Engl J Med 1961;265:65-68

11 Landsberger D, Rav'e D, Friedman G. The skull in chronic sarcoidosis. Postgrad Med J 1988;64(757):875-877

12 Stern BJ. Neurological complications of sarcoidosis. Curr Opin Neurol 2004;17(03):311-316

13 Nowak DA, Widenka DC. Neurosarcoidosis: a review of its intracranial manifestation. J Neurol 2001;248(05):363-372

14 Fritz D, van de Beek D, Brouwer MC. Clinical features, treatment and outcome in neurosarcoidosis: systematic review and metaanalysis. BMC Neurol 2016;16(01):220

15 Hoitsma E, Faber CG, Drent M, Sharma OP. Neurosarcoidosis: a clinical dilemma. Lancet Neurol 2004;3(07):397-407 